\title{
The role of local government in the control and supervision of urban construction, with an emphasis on old texture
}

\author{
Elham AMINI $^{1}{ }^{*}$, Majid NAGHAVI $^{3}$, Adel GorJINIA $^{2}$, Saeid Madadi BAROOGH ${ }^{4}$, \\ and Hamid Reza Mirza ALI \\ ${ }^{1}$ Assistant Professor Islamic Azad University, Pardis Branch, Tehran, Iran \\ ${ }^{2}$ Department of Design and Urban and Regional Planning, Islamic Azad University, Science \\ and Research Branch, Tehran, Iran \\ ${ }^{3}$ Ph.D. Student in Urban Planning Azad University, Tehran Shomal Branch, Tehran, Iran \\ ${ }^{4}$ Graduate student of Software Engineering, Islamic Azad University, South Tehran, and \\ Tehran, Iran \\ ${ }^{5}$ Graduate student of urban management, Islamic Azad University Central Tehran Branch
}

\begin{abstract}
Marginalization and informal settlements in present terms, the consequences of rapid urbanization and industrialization is transferred to the social and economic paradigm. In our increasingly urban development, management and organization of all the issues and complexities caused due to failure in the field of urban management is crystallization. One of the things that have been added to the mass of urban management problems and given the current trend of urbanization in the world, as the crisis worsened and engraved on the forehead and sees its own sensitivities raised the issue of neighborhoods is informal, That should be analyzed in the field of urban management as a root and a clear strategy and fundamental decisions in this regard. The main purpose of this paper is the role of urban management in the control and monitoring of urban construction with an emphasis on informal settlements in the Eslamshahr. Methods: In this cross-sectional study is, according to its nature as a research and information gathered from documents and descriptive written sources was organized. The results show that the best way to start a new process of development in the communities, monitoring construction in the settlements and organization of their physical capabilities during the empowerment strategy is implemented.
\end{abstract}

Keywords: informal settlements, control and monitoring, urban management, urban planning.

\section{Introduction}

After several decades of planning and programs as a result they use the common patterns in different countries is urban construction, It was expected that the city is based on the correct principles and rules with regard to the potential economic, social, cultural and regional growth and developed. Unfortunately, these models not only failed to respond to the real needs of cities in general but also snapped obstacles and problems. Urban factors in each country function of the system governing the society, and although Urban Planning, and certain countries follow similar patterns and tools required in accordance with the general rules of supply and regulate urban development (maziyati, 1377). However, due to different political and socio-economic structures in each country has different features, distinguishes them from each other (gharib, 1980). Thus, the patterns of urban development planning and design cannot be considered as something separate and individual, Because this type of planning is one of the levels of physical planning policies must fully comply with the policies 
of the higher levels (Saeed Nia, 1379). In other words, the structure of each country's initial conditions to explain the spatial planning of urban studies. In addition, laws and regulations related to the implementation of the planned platform is designed patterns and meet the conditions for recognition of patterns is construction. Also check the performance of institutions and organizations involved in the planning, tools and procedures, and finally to identify patterns of urban construction leads in each country (maziyati, 1379). Obviously, the knowledge or the use of any model without considering the above-mentioned elements, it will cause malfunction pattern or inefficiency. Guidance and control system of urban construction in the country are affected by the social, legal and planning. Based on this guidance and control of urban construction in the country is formed in two ways: first, through a variety of programs, projects, 2 through planning tools and Urban Development (Legal and financial instruments). The system of qualified institutional bottlenecks and problems in the preparation, review, approval, implementation and monitoring of urban development projects and the root of many problems in the failure of the legal, structural and institutional communication lies more to the point is (Saeedniya, 1379 and the Ministry of housing and Urban Development, 1388). Urban construction system rather than based on needs, goals and opportunities are municipalities on policy, facilities and views of the central government is firm and uncompromising in accordance with the documents approved by the experts (the producer) and the central government Comments (passage) is (Majedi and colleagues, 1378). Which is then communicated to run municipalities and more hierarchical and physical nature of these projects and developments stand in front of the (Zista, 1372). This system of urban construction in the country shows the country of the German system of government direct intervention and maximum state and municipal buildings can be seen in the control (ARL, 2005). British common law system and control system in the country is more open structure and emphasis on building control and compliance by the private sector than the rights of third parties (neighbors and environmentalists will be awarded to urban construction (Hall, 1994). France as a country with Centralized not traditional system, the law is less flexible and are also involved in aspects of quality and technical standards at the municipal building can be seen, instead of the most comprehensive insurance and guarantee system to ensure quality standards than is (Ghaffari, 1382). The need to examine ways to control urban construction project in two aspects: First, attention to proper and effective methods to guide and control urban construction or negative consequences have followed And second, that according to the country's current situation by making some changes in the rules and structure of the current system and ready to accept further changes, What strategies for overcoming the constraints of urban construction in the country is predictable. Settlements car with words such as informal settlements, marginalization and the like have been defined in recent years in all cities of the country, especially in the metropolitan area of Tehran strongly growing is, to the extent that about 20 to 30 percent of the population of Tehran in these settlements live And the proportion with respect to the structure and trends of population growth and migration will also be increased.

\section{Theoretical Foundations of Research}

Urban patterns and problems and deficiencies in the preparation of urban development is long. Urban affairs experts in academia, public and private sectors have different views about the context and content of the plan and their suitability to the needs of urban development, the country can offer. Therefore, this issue is not new, but it can be stated with confidence that solutions are comprehensive and thorough remedial shortcomings urban development and respond to the growing needs of today's citizens, not developed. In recent years, urban problems are much more complex than before. Issues such as housing, traffic, wear fabrics, providing services for the urban economy, urban physical environment and have been critical 
step necessary to find a solution to the crisis is more urban than ever (Kalhorniya, 1387, 32). One of the biggest deficiencies in Iran's urban planning and lack of regular and systematic plan for the city is on edge. At the edge of nature and animal life in the invasion of the withdrawal of the physical development of cities. Villages, gardens, farmland, subterranean life thousands of years gradually destroyed and replaced with streets, buildings, stone and cement, respectively. Life wave attack edges of the leading cities in the more informal places of colonies formed on the edges (Engineering, 1385, 46). Considering the growth of increasing urbanization, poverty and deprivation is pivotal issues that cities face. The growing phenomenon of urban poverty and deepening income gap caused in large cities, where low-income groups in most communities in specific geographic areas are formed from the remains of the so-called development are marginalized. These groups of immigrants and citizens with the hope of improving the lives that have taken a step in a long way, and to accept risks and work conditions in the informal housing and after much effort compensation for disability in the provision of their needs in official the way to ensure their survival in the city. The emergence and growth of informal settlements and housing abnormal phenomenon in cities and their margins are a variety of reasons. These arose from the different levels of mismanagement of crystallization is more conspicuously than other issues. Lack of proper distribution of wealth and power between regions and sectors score in the country has led to an imbalance in the regional and local levels, and consequently rich in marginalized areas, it is. The population distribution of stability in a deep divide their attention they flock to the cities (Masoumi, 1387, 23). Vulnerable neighborhoods in search of shelter in the informal and ill-equipped, affordable land and housing ownership informal, Low-income households in urban areas would free the rental costs of the traps, but low-income families rent rooms by converting to a civilian shelter in the margin, is faced with severe deprivation service, Because the marginal settlements are generally based on length of service centers in the city were formed. This factor is one of the reasons granted the land in this area. Areas is characterized by more informal neighborhoods are the city limits, In terms of planning and urban development standards and urban services are lacking. Water and electricity to the residents in these areas is difficult, there is no infrastructure in these areas and communication routes to these areas is faced with many problems, Police supervision as a key element in urban management to reintegrate into urban areas and to prevent crime in urban areas is a major weakness. In terms of a systematic program of education for the children's education and for adult education and training in how to deal with the problems of urban citizenship can be seen a large decline (Shabani, 1384, 24). To deal with the growing trend of informal neighborhoods, the first step should be to review major national policies and urban management structure change. (It's a matter of organization and settlement patterns in the country and the government's commitment to it). These neighborhoods are generally abnormal environment and social problems that are motivating argument sometimes upside down, because of the emergence of these settlements are considered. Although the physical condition of the materials used in informal areas, per capita housing and social services and infrastructure worsened the situation in many countries of the South, However, compared with other urban areas of deprivation and discrimination, poverty, corruption, growing social and anti-sustainable human development is critical to focus. Informal neighborhood adjacent to the city in the past and today, located in the heart of cities, the barriers play a key role in national development and leading cities in the use of opportunities arising from globalization of the economy, And where there is no doubt that the process of globalization, many citizens are marginalized and deprived of social support (Sarrafi, 1388, 6). Urban infrastructure development over the past two decades in Iran, would benefit the majority of people living in the neighborhood of drinking water, electricity and gas piping is. But despite the provision of infrastructure, informal settlements lacking minimum facilities, service centers, education, 
health, security, and cultural landscape. The land on which the residential neighborhoods and the lives of low-income households and the urban environment, increased price increase, As a result of land speculation, with infinite resolution and exchange programs and prospects of development of residential areas without adequate services and pathways to can be seen. Experience has shown that impede the realization of anticipated current trends in the development of urban spaces and service spaces outside of urban areas, particularly on the core areas of the informal. The minimum reserve land without land bank services in informal settlements and streets, Cannot provide services to low-income populations living in these areas have hope (khatem, 1387, 4). The devastating consequences of the neighborhoods in the cities, the development of social corruption The increase in theft, robbery, moral corruption and prostitution, drugs, murder, looting and beggary of the consequences of migration, which is manifested in the form of informal and low level of life in the countryside is crystallized, Security and crime problem in this place is. As noted earlier, these areas because of falling away from the heart of the city, the gap between the standard of living was different from other segments of society. View these differences and how to deal with marginalized people and stress from factors mentioned in the spontaneous character of the crime rears (Piran, $1383,27)$. The program has been developed, partially or not implemented at all, it could be explained that in the past, the prevailing view that urban managers from social weakness of this class as a community problem, and Instead of trying to improve and enable the Group to benefit from infrastructure and services in urban and remote from the heart of the city, try to remove and clean the area without considering the consequences. This view is mostly due to the incompetence, mismanagement, agencies involved in urban management and coordination between the control and investigation of the settlements and their residents were financial debility. The aim of this phenomenon and use the bulldozer to clear neighborhoods without basic thinking and evaluating norms and behaviors in society about its consequences can cause big problems, The obvious example of which can be seen in the neighborhood of Tehran white soil. The degradation of the situation to build and manage a physical point of view, regardless of the people as the main pillar of the city. It seems that the people and for the people, not programs can lead to good results. Eating on the local system and the lack of formal control and reduction of social activities is not an easy urban Stations of the easily overlook.

\subsection{The concept of marginalization and informal settlements}

Marginalization and slums, slum dwellers, nomadic, slum dwellers are all in a sense, and if we give a definition of these terms, we should say: Marginalized people who live within the city economically, but the absorption of the economic system - not social "(Asghari zamani, 1383, p. 40). Marginalized people also said that because of economic problems in the city and outskirts taken refuge resistance not to be safe in the cost of living in the center, and other definition can be said: Marginalized people who, because of poor funding due to the economic power, have failed to residents living in the central adjust to the lack of social adjustment can migrate to areas that could be attracting they provide "(Etemad, 1381, p. 32).

\subsection{Issues and problems, needs and priorities Neighborhood}

In this neighborhood and adjacent neighborhoods due to the lack of adequate treatment centers as well as in some of the homes and health issues by residents and non-compliance, the level of public health is very low. On the other hand, the accumulation of waste and building materials along with the streets and the sound of the pollution problems in this area. As well as the lack of principle and construction of the safety in times of danger and accidents in order to relief the localities. 
But according to the results obtained from this study and from interviews with residents for this location, lack of recreational and welfare services and basic needs based on the priority of this area in the form of the table is shown below:

Table 1: the problems, needs and priorities of the neighborhoods on the basis of the findings

\begin{tabular}{||c||c||c||}
\hline \hline Row & Problems and needs & Priority \\
\hline $\mathbf{1}$ & Document of endowment + covered passages & The first priority \\
\hline $\mathbf{2}$ & Collection and disposal of garbage cleaning + passages & The second priority \\
\hline $\mathbf{3}$ & $\begin{array}{c}\text { The creation and expansion of public transport to the } \\
\text { city center }\end{array}$ & The third priority \\
\hline $\mathbf{4}$ & $\begin{array}{c}\text { Create a clinic and pharmacy boarding + Park and } \\
\text { green space }\end{array}$ & The fourth priority \\
\hline $\mathbf{5}$ & Create space + sewage network & Priority pinch \\
\hline $\mathbf{6}$ & Cultural spaces devoted to the city & The sixth priority \\
\hline \hline
\end{tabular}

Source: (field study authors)

\section{Research findings}

Iran settlements vulnerable position compared to other countries is different. Of settlements in vulnerable developing countries to 50 percent of the population is urban, while in Iran, this ratio is only 0.9 per cent of urban housing is formed. Manufacturers rarely captured in informal housing without paying the price of their actions often provide land to the informal market. Mentioned conditions, spatial planning and housing development in Iran, due to the high index of relative prosperity resulting from the accumulation of oil revenues, much easier than other developing countries would be necessary to organize and empower residents of these tissues.

\subsection{Strategies and policies for urban management in the organization of informal settlements}

\section{A) A policy of neglect or indifference}

Due to the transition from traditional society to a modern industrial and urban societies, the emergence and persistence of informal settlements in Third World societies also normal. The proposed solution, the tolerance of such places and drop it in the invisible hand of the market, whatever your choice will appreciate the thought. Of course, the occasional poor housing projects and affordable housing should resonate in the media and limited plans are put into practice (Piran, 1366, p. 35). However, this theory can be seen a kind of determinism and structuralism and optimistic attitude towards the subject, but the rural exodus to the big cities to renounce the comfort of residents is considered lucky (Bigdeli, 1383, p. 65).

\section{B) Changes in the socio-economic system and the structure of society}

Theorists any action against the capitalist system in order to balance economic and social environment of the developing countries it impossible to know, And even exacerbate the imbalance as they are subject to the elimination of the phenomenon removal systems knew that in any way connected with global capitalism, In this view, there is also a kind of determinism and structuralism compared to the extremely pessimistic. The plan is useless to solve the problem of informal settlements. However, in this theory, the rural exodus to the big cities and condemned denial is considered a sign of global capitalism is a dependency. Adjustment and transformation of these two ideas led in the second half of the 1980 s to 
replace the word slum, slums, informal settlements rooms off ... the term for a variety of urban housing immigrants out of the official rule, be chosen. This is a sign that the phenomenon is not only due to economic development, but also related to planning, especially planning body (Bigdeli, 1383, p. 67).

\section{C) The policy of destruction and dispersion}

This policy is only implemented pessimistic attitude towards the phenomenon of informal settlements and the displacement of its residents. This means that the most basic and most common way of dealing with the phenomenon of informal settlements and planning from an academic point of view is the most hated practices. It will not only effect the removal of informal settlements, but would also provide distribution and aggravation. On the other hand, in this view, Main and auxiliary agents emergence of informal settlements Informal settlements but that is a function, not given. The phenomenon of informal settlements consequence of the evolution and development of the historical, social, economic and political communities and stemming from macroeconomic policy planning. The community (in the sense of the people), and especially planners are required to address the root causes of informal settlements and superstructure work of the above methods Manila Executive samples destroyed about 3 thousand huts and forcible transfer of about 11 thousand people named. In Tehran in various areas: 2, 14, 16 method is implemented, so that in districts 2 and 14 is repeated several times. Like the appearance of moderation, and compromise it's populist in the 16 municipalities of the hut dwellers Ali Abad, which is to come into force in 1986.

\section{D) The construction of social housing}

The primary orientation Southern states after dealing with informal settlements and bad housing, the housing standard for the transfer of the residents of the buildings, It was common in the 1960s, usually in urban areas took place reconstruction projects or improvements. And special programs and comprehensive low-income housing there. Instead, regulations and limits of an attempt to create a barrier to migration and the migrants came to the city, to be deprived of their accommodation. Thirteen dormitory established in November 1340 for relocation of slum dwellers in the city of Tehran, is this. At the same time there was a new program for low-income settlement and the severity of their presence in Tehran of the law, is prohibited.

\section{E) Provide land and services}

Following the failure of the strategies of social housing in the 1970s, the programs and services with the approval and assistance of the World Bank was common in the South. The strategy of the government to provide land for low income at least rely on network infrastructure and is trying to get money from users. The use of self-help in the common strategy and to upgrade existing huts and marginalization are used. This strategy has three main axes purpose or that include:

Receptivity, which means that housing prices by applying the standards and practices suitable for families tolerable level be lowered, The government has to pay heavy subsidies are not necessary. Return on investment, return on investment means that as much as possible to come to repeat it. Repeat the respondents, the return on investment and financial power of the state, there is the possibility of repeating the project. This strategy was completed in 1970 and welcomed in most countries of the South to be implemented, but after a while it became apparent shortcomings. Apart from that, according to political criticism that the strategy will be to stabilize the capitalist system. The inability of management problems, the inability of low-income groups in lower costs, meet some of the groups (informal settlement) and the abstraction of the system of market relations and financial planning or construction is 
considered. The experience of the World Bank conclude that to solve the problem of lowincome requires more elaborate and interconnected relationship between the market more government and household.

\section{I) liberalization and economic stabilization}

A new approach to housing was created and quickly affected by the policies of liberalization and economic stabilization were called. The International Monetary Fund and the World Bank were major advertisers and promoters. The difference is that the IMF economic stabilization policies too, but the World Bank is due to the relative economic development issues simply do not pay. The results of these policies in countries of the South in general was not satisfactory, So that in Latin America in the 1980s, the decade was called Gone with the Wind and in particular in the housing sector as well as the bad aspects of housing and marginalization in most developing countries increased. For example preferable rates (which also was used in Iran the preparation of projects) could help to improve the situation of low-income housing.

\section{D) Empowerment policy}

In the late 1980s, policies of liberalization and economic stabilization of the housing policy in general and specifically criticized, and the need for change was obvious. This change is the need to balance between the public and private general and not rely on onesided focus on one of them. This approach is not limited to the World Bank and the International Monetary Fund, but this time the experience was summed up in the United Nations Centre for Human Settlement Development programs developed by the United Nations and the World Bank which had been held. This approach has taken the name of empowerment, with the approval of the General Assembly of the United Nations became a shelter strategy. The approach to housing policy, which can be in the form of a new approach to development economics is called the basic needs, social and economic issues will be treated equally. And this time the full-scale strives to individual projects for low-income housing to the economy's macroeconomic planning physical and financial markets, bond calls.

\subsection{The rules and criteria for the control and supervision of construction work - Citizenship and Urban Renovation and Development Act (1347 with subsequent amendments)}

Law and its content on the urban development process and how to monitor and regulate the construction and urban municipalities anticipated legal measures to deal with violations of urban construction, the payment of renewal and urban development to the municipalities and the like. In this sense the law should refer to the rights and duties of citizens, but the study also did not show the content of the law. What comes from the law, including the legal relationship between individuals and municipalities regulate the economic relationship with the word tax - complications (Nejati Hosseini, 1378, 83).

\section{- Citizenship and the building control engineering system (approved in 1375)}

The Constitution drafting legal regulations and control of engineering systems of the building. In Article 2 of the law to strengthen and expand culture and Islamic architecture, urban planning, engineering growth, the benefits of trade and engineers discussed. Only package that will connect with local community members, paragraph 4 of that Article, In which to promote the principles of architecture and urbanism and growing public awareness about the principles and provisions of the National Building and increase productivity has been mentioned. The law as a covenant of the construction of the word citizen is not used instead of the term is generally used. While this system as a non-governmental organization (NGO) plays and (NGO) and one of the pillars of local civil society. 


\section{Conclusion}

The world's rapidly expanding urban life. Rapid urbanization in developing countries than in developed countries. Along with the rapid pace of urbanization and rapid in Iran, and this trend accelerated problems for many cities have followed. As urbanization without the intellectual and operational control and the development of physical infrastructure in which the Earth is not inflation, housing prices have fueled further informal development of unconventional problem. All those involved in development issues believe that the unbalanced development of economic, social and cultural causes of eating is the relationship between urban and rural areas. In addition, the new climate problems such as drought, massive hard living conditions in villages and rural to urban areas, followed by numerous groups have emigrated. The immigration control measures such as rural development and so on are not led.

\section{In order to formalize informal settlements activities in the community is better:}

- Strengthening the urban poor in different forms and advance the development of these communities.

- To clean the undesirable elements and anti-social support and improve public safety. Followed by the local community is more secure environment for investment, in addition to the legal rights and of the possibility of the emergence of indigenous leadership among the poor increases. Formal to the informal sector, in addition to the above, have access to financial resources, formal education is possible and can be paid for urban management and increase overall productivity. As well as the support of the official formal (financial and training) that the quality of goods and services in this sector has increased as a result of improved economic conditions lead employees and the local community.

\section{Municipality in organizing informal areas around the two main strategies that include:}

- Improve the status quo by organizing, empowering the population and the distribution of resources between the center and the edge of the city proper income to improve their general situation.

- Deterrence and reducing the informal and illegal settlements dwellers in this building in the city, police and local cooperation in this field could be very useful.

\section{Resources}

1. Etemad, ghiti, urbanization in Iran, Tehran, aghah, year 1381.

2. Bahram Ghaffari, M., (1382), studies to improve control and urban construction projects, technical consulting and engineering organization in Tehran.

3. Piran, Parviz, rapid urbanization and inconsistencies in Tehran slum dwellers, the magazine of political information - economic, numbers 1,3,4,5,7 year 1366 .

4. Piran, P., (1387), the informal settlements to accommodate rare, seven cities in search of solutions,

5. Riahi, K., (1381), where the phenomenon of suburbanization Tehran to win Etemad issue.

6. Zista (Consulting Engineers Planners), (1372), assessment of urban master plans in Iran, Tehran: Plan and Budget Organization.

7. Kalhorniya, B., (1387), promotion and empowerment of urban poor structures, patterns of conventional patterns of urban regeneration in Quarterly No. 10 regional.

8. Saeedniya, A., (1379), the revision of the definitions, concepts and contents of urban development plans, Tehran: Ministry of Housing and Urban Development, Research and Studies Center of Planning and Architecture.

9. Sarafi, M., 1381 to the idea to organize formal settlements of suburbanization and urban context ", seven cities, in the third, eighth numbers. 
10. 1 Azimi, A. (b), (1375), Urban development laws in France, Comparative Urban Rules, Volume II, Tehran: Office of Studies and Planning of the Ministry of Housing and Urban Development standards.

11. Majedi, H. et al., (1378), The foundations of a comprehensive urban design frameworks revised ToR, Tehran: Ministry of Urban Planning.

12. Maziyati, M., (1379), Urban and rural management in Iran, and the problems of its features, Tehran: Ministry of Housing and Urban Development, the National Land and housing. 